\title{
Lysophosphatidic acid regulates inflammation-related genes in human endothelial cells through $\mathrm{LPA}_{1}$ and $\mathrm{LPA}_{3}$
}

\author{
Chi-Iou Lin ${ }^{\mathrm{a}, 1}$, Chiung-Nien Chen ${ }^{\mathrm{c}, \mathrm{d}, \mathrm{f}, 1}$, Po-Wei Lin ${ }^{\mathrm{a}}$, King-Jen Chang ${ }^{\mathrm{d}}$, \\ Fong-Jou Hsieh ${ }^{\mathrm{b}, \mathrm{e}}$, Hsinyu Lee ${ }^{\mathrm{a}, \mathrm{b}, \mathrm{c}, \mathrm{d}, *}$ \\ ${ }^{a}$ Institute of Zoology, National Taiwan University, Taipei 106, Taiwan, ROC \\ ${ }^{\mathrm{b}}$ Department of Life Science, National Taiwan University, Taipei 106, Taiwan, ROC \\ c Angiogenesis Research Center, National Taiwan University, Taipei 106, Taiwan, ROC \\ ${ }^{\mathrm{d}}$ Department of Surgery, National Taiwan University Hospital, Taipei 106, Taiwan, ROC \\ e Department of Medical Ultrasound, National Taiwan University Hospital, Taipei 106, Taiwan, ROC \\ ${ }^{\mathrm{f}}$ Division of Mechanics, Research Center for Applied Sciences, Academia Sinica, Taipei 115, Taiwan, ROC
}

Received 14 September 2007

Available online 1 October 2007

\begin{abstract}
Lysophosphatidic acid (LPA) is a low-molecular-weight lysophospholipid (LPL), which regulates endothelial cells participating in inflammation processes via interactions with endothelial differentiation gene (Edg) family G protein-coupled receptors. In this study, we attempted to determine which LPA receptors mediate the inflammatory response in human endothelial cells. Introduction of siRNA against LPA $_{1}$ significantly suppressed LPA-induced ICAM-1 mRNA, total protein, and cell surface expressions, and subsequent U937 monocyte adhesion to LPA-treated human umbilical endothelial cells (HUVECs). By knock down of LPA 1 and LPA 3 in HUVECs, LPA-enhanced IL-1 $\beta$ mRNA expression was significantly attenuated. Moreover, $\mathrm{LPA}_{1}$ and $\mathrm{LPA}_{3}$ siRNA also inhibited LPA-enhanced IL-1-dependent long-term IL-8 and MCP-1 mRNA expression, and subsequent THP-1 cell chemotaxis toward LPA-treated HUVECconditioned media. These results suggest that the expression of LPA-induced inflammatory response genes is mediated by LPA 1 and $\mathrm{LPA}_{3}$. Our findings suggest the possible utilization of $\mathrm{LPA}_{1}$ or $\mathrm{LPA}_{3}$ as drug targets to treat severe inflammation.
\end{abstract}

(C) 2007 Elsevier Inc. All rights reserved.

Keywords: LPA; $\mathrm{LPA}_{1} ; \mathrm{LPA}_{3}$; Endothelial cells

Lysophosphatidic acid (LPA) is a multifunctional bioactive lipid mediator generated by enzymatic cleavage of cell membrane phospholipids, present in human plasma, biological fluids, and tissues [1]. By binding to specific G-protein-coupled receptors (GPCRs), LPA mediates many cellular responses, including cell differentiation, proliferation, and migration and wound healing [2-4]. LPA acts on at least five LPA receptors $\left(\mathrm{LPA}_{1-5}\right)$. Three of these $\mathrm{LPA}$ receptors, $\mathrm{LPA}_{1} / \mathrm{Edg} 2$ [5], $\mathrm{LPA}_{2} / \mathrm{Edg} 4$ [6], and LPA/Edg7 [7], are members of the endothelial differentia-

\footnotetext{
* Corresponding author. Address: Institute of Zoology, National Taiwan University, Taipei 106, Taiwan, ROC. Fax: +886 223636837.

E-mail address: hsinyu@ntu.edu.tw (H. Lee).

${ }^{1}$ These authors contribute equally to this work.
}

tion gene $(\mathrm{Edg})$ receptor family $[1,8]$. The fourth receptor, $\mathrm{P} 2 \mathrm{Y} 9 / \mathrm{LPA}_{4}$, is closely related to purinergic receptors [9]. The orphan receptor, GPR92, was recently confirmed to be the fifth LPA receptor $\left(\mathrm{LPA}_{5}\right)$, which might have physiological functions distinct from those of $\mathrm{LPA}_{1-4}$ [10].

LPA receptors transduce diverse heterologous signal pathways through coupling with multiple $G$ proteins, including $\mathrm{G}_{\mathrm{q} / 11}, \mathrm{G}_{\mathrm{i} / \mathrm{o}}$, and $\mathrm{G}_{12 / 13}$ [2]. $\mathrm{LPA}_{1}$ displays weak coupling to $\mathrm{Gq}$ but efficiently couples to $\mathrm{Gi}$ and $\mathrm{G}_{12 / 13}$. In contrast, $\mathrm{LPA}_{2}$ and $\mathrm{LPA}_{3}$ can effectively couple to $\mathrm{Gq}$, which triggers calcium signaling and activates PKC. In addition, $\mathrm{LPA}_{2}$ can also couple to $\mathrm{G}_{12 / 13}$ [11]. In the RH7777 cell line, an LPA-unresponsive rat hepatoma cell line, which stably transfects $\mathrm{LPA}_{1}$, affected inhibition of cAMP accumulation, whereas $\mathrm{LPA}_{2}$ and $\mathrm{LPA}_{3}$ mediated 
calcium mobilization. The inhibition of cAMP accumulation is pertussis toxin-sensitive [6]. These results further confirm that $\mathrm{LPA}_{1}$ is Gi-linked, whereas $\mathrm{LPA}_{2}$ and $\mathrm{LPA}_{3}$ are Gq-linked. Our previous studies demonstrated that LPA enhances monocyte-endothelial cell adhesion and monocyte chemotaxis toward endothelial cells through the respective upregulation of ICAM-1 and IL-1-dependent chemokine IL-8 and MCP-1 expressions in endothelial cells, thus promoting inflammation processes [12,13]. However, which LPA receptors mediate these inflammatory-related gene expressions in endothelial cells in terms of modulating inflammation processes remains unclear [14].

Loss-of-function genetic or pharmacologic approaches are required to determine the functions of LPA receptors in vivo [15]. However $\mathrm{LPA}_{1}^{-/-}$mice display various severe phenotypic abnormalities and approximately $50 \%$ neonatal lethality due to defective suckling and olfaction dysfunction [16]. There are no available specific pharmacologic tools appropriate for the knock down of these receptors. Therefore, we utilized siRNA technology, which is reported to initiate the mechanism of posttranscriptional gene silencing to determine the roles of LPA receptors in endothelial cells. In this report, by specifically suppressing LPA receptor gene expressions in HUVECs, we present evidence that LPA-upregulated ICAM-1 mRNA, total protein, cell surface expressions, and subsequent cell adhesion of U937 cells with LPA-treated HUVECs are largely mediated by $\mathrm{LPA}_{1}$ moreover, LPA-enhanced IL- $1 \beta \mathrm{mRNA}$ expression, and subsequent IL-1-dependent IL-8 and MCP-1 mRNA expressions in response to LPA are mediated through both $\mathrm{LPA}_{1}$ and $\mathrm{LPA}_{3}$. In addition, $\mathrm{LPA}_{1}$ and $\mathrm{LPA}_{3}$ also mediate THP-1 cell chemotaxis toward LPA-treated HUVEC-conditioned media. These results suggest that the binding of LPA to $\mathrm{LPA}_{1}$ and $\mathrm{LPA}_{3}$ modulates ICAM-1, IL-1 $\beta$, IL-8, and MCP-1 gene expressions, which contribute to monocyte/endothelium adhesion and chemoattraction toward the endothelium, thus facilitating inflammation processes.

\section{Methods}

Materials. LPA, sphingosine 1-phosphate (S1P), fatty acid-free bovine serum albumin (FAF-BSA), and lipopolysaccharide (LPS) were purchased from Sigma (St. Louis, MO). The human ICAM-1 antibody (clone M19) and FITC-conjugated mouse anti-human ICAM-1 monoclonal antibody (clone 6.5B5) were purchased from Santa Cruz Biotechnology (Santa Cruz, CA). Horseradish peroxidase-conjugated goat anti-mouse IgG was obtained from Boehringer Mannheim (Indianapolis, IN).

Cell culture. HUVECs were isolated from fresh umbilical cords (IRB: 9561709146, National Taiwan University Hospital) as described previously [12] and were cultured in M199 medium supplemented with $10 \%$ FBS and 25\% EGM (Cell Applications, San Diego, CA). U937 and THP-1 cells were cultured in RPMI-1640 medium (Gibco, Grand Island, NY) supplemented with $10 \%$ FBS. Cells were maintained under standard cell culture condition at $37{ }^{\circ} \mathrm{C}$ in humidified air with $5 \% \mathrm{CO}_{2}$.

RT-PCR analysis. Total cellular RNA was extracted from HUVECs using the TRIzol reagent (Gibco), and a Superscript kit (Gibco) was used for the reverse-transcription (RT) synthesis of cDNA. Polymerase chain reaction (PCR) amplification was performed with Taq DNA polymerase (Geneaid, Taoyuan, Taiwan) using the following sets of primers: $5^{\prime}-\mathrm{GC}$
AAGCTCCCAGTGAAATGCAAAC-3' and 5'-TGTCTACTGACCCC AACCCTTGATG-3' (ICAM-1), 5'-AAACAGATGAAGTGCTCCTT CAGG- ${ }^{\prime}$ and $5^{\prime}$-TGGAGAACACCACTTGTTGCTCCA-3' (IL-1 $\beta$ ), $5^{\prime}$ ATGACTTCCAAGCTGGCCGTGGCT- $3^{\prime}$ and $5^{\prime}$-TCTCAGCCCTCT TCAAAAACTTCTC-3' (IL-8), 5'-TCTCAGTGCAGAGGCTCGCGA$3^{\prime}$ and 5'-GAGTGAGTGTTCAAGTCTTCG-3' (MCP-1), 5'-ACCA CAGTTCATGCCATCAC- $3^{\prime}$ and $5^{\prime}$-TCCACCACCCTGTTGCTGTA$3^{\prime}$ (GAPDH), 5'-CGGAGACTGACTGTCAGCA-3' and 5'-GGTCCA GAACTATGCCGAGA-3' $\left(\right.$ LPA $\left._{1}\right), 5^{\prime}$-AGCTGCACAGCCGCCTGCC CCGT- $3^{\prime}$ and $5^{\prime}$-TGCTGTGCCATGCCAGACCTTGTC-3' $\left(\right.$ LPA $\left._{2}\right)$, and 5'-TTAGCTGCTGCCGATTTCTT- $3^{\prime}$ and $5^{\prime}$-ATGATGAGGAAGGCC ATGAG-3' $\left(\mathrm{LPA}_{3}\right)$. PCR products were resolved on $2 \%$ agarose gels, stained with ethidium bromide, and then photographed.

Cell transfections. Sequences of used siRNA were UUCUCCGAACGU GUUCACGUdTdT, and ACGUGACACGUUCGGAGAAdTdT (scrambled), and CCGCCGCUUCCAUUUUUCCUdTdT, and AGGAA AAAUGGAAGCGGCGGGdTdT $\left(\mathrm{LPA}_{1}\right)$. LPA $\mathrm{L}_{3}$ siRNA was purchased from Santa Cruz Biotechnology. HUVECs were transfected using the optimized protocol for electroporation of HUVECs with the Nucleofector apparatus (Amaxa Biosystems, Cologne, Germany) as described previously [17].

Western blotting for ICAM-1. Treated cells were lysed in RIPA buffer ( $150 \mathrm{mM} \mathrm{NaCl}, 1.0 \%$ Nonidet P-40, $0.5 \%$ deoxycholate, $0.1 \%$ SDS, and $50 \mathrm{mM}$ Tris; $\mathrm{pH} 8.0$ ) containing a protease inhibitor cocktail (Sigma) and $2 \mathrm{mM} \mathrm{Na}$ vanadate. After removing the cell debris by centrifugation at $13,500 \mathrm{rpm}$ for $5 \mathrm{~min}$, the protein concentration was determined by the Bradford assay. Samples containing equal amounts of proteins $(50 \mu \mathrm{g})$ were separated by $10 \%$ SDS-PAGE and electrophoretically transferred to a PVDF membrane (Millipore, Bedford, MA). The membranes were blocked with $5 \%$ BSA in a Tris-buffered saline-Tween 20 solution. The blots were performed as described previously [17]. The blots were stripped and reprobed for $\beta$-actin to demonstrate uniform loading of proteins.

FACscan. Transfected HUVEC cultures were serum-starved for $16 \mathrm{~h}$ and incubated with LPA or S1P for $8 \mathrm{~h}$ at $37^{\circ} \mathrm{C}$. Suspensions of $10^{6}$ HUVECs in PBS $(200 \mu \mathrm{l})$ with $0.1 \%$ fatty acid-free BSA received $2 \mu \mathrm{l}$ of FITC-conjugated human anti-ICAM-1 and were incubated for $30 \mathrm{~min}$ at $4{ }^{\circ} \mathrm{C}$. Antibody binding of HUVECs with and without stimulation was determined by CyFlow ${ }^{\circledR}$ SL (Partec, Münster, Germany) and analyzed by WinMDI version 2.8 software.

In vitro adhesion assay. Transfected HUVECs were cultured in six-well plates and stimulated with $5 \mu \mathrm{M}$ LPA or S1P for $8 \mathrm{~h}$. After washing with M199 medium, U937 monocytes $\left(1 \mathrm{ml}, 5 \times 10^{6}\right.$ cells $\left./ \mathrm{ml}\right)$ were added to the cultures and then incubated at $37^{\circ} \mathrm{C}$ for $1 \mathrm{~h}$. Cultures were washed with M199 medium until no visible suspension of U937 cells was observed and then imaged by microscopy. The number of monocytes per culture was counted.

Chemotaxis assay. The transwell migration of human THP-1 cells toward conditioned media was studied in a 48 -well microchamber (Neuro Probe, Cabin John, MD) as described previously [13]. Cells migrating across the filter onto the lower surface were photographed using light microscopy. Quantification of the migration results was determined by the color intensity of the spots solubilized by solubilization buffer, and the absorbance was determined at $540 \mathrm{~nm}$.

Statistical analysis. Significant differences between control and treatment groups were determined by ANOVA. Each experiment was repeated at least three times. The results are expressed as means \pm SE. A value of $p<0.05$ was considered statistically significant.

\section{Results}

LPA-induced ICAM-1 mRNA expression is mediated through $L P A_{1}$, while IL-1- and IL-1-dependent IL-8 and $M C P-1$ MRNA expressions are mediated through $L P A_{1}$ and $\mathrm{LPA}_{3}$ in HUVECS

We first determined the LPA receptor expression profiles in HUVECs by RT-PCR. Our results indicated that 
A
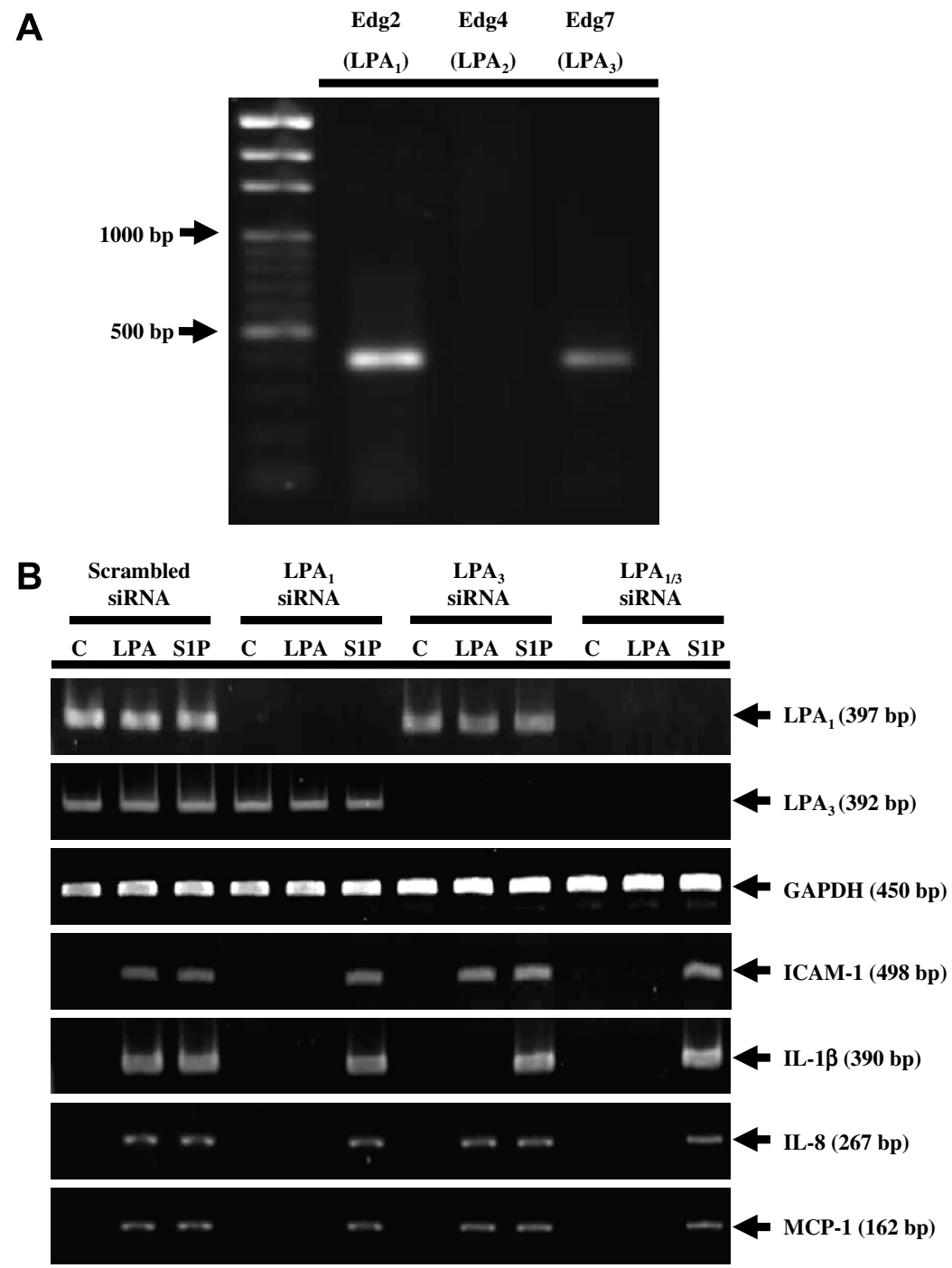

Treatment: $4 \mathrm{~h}$

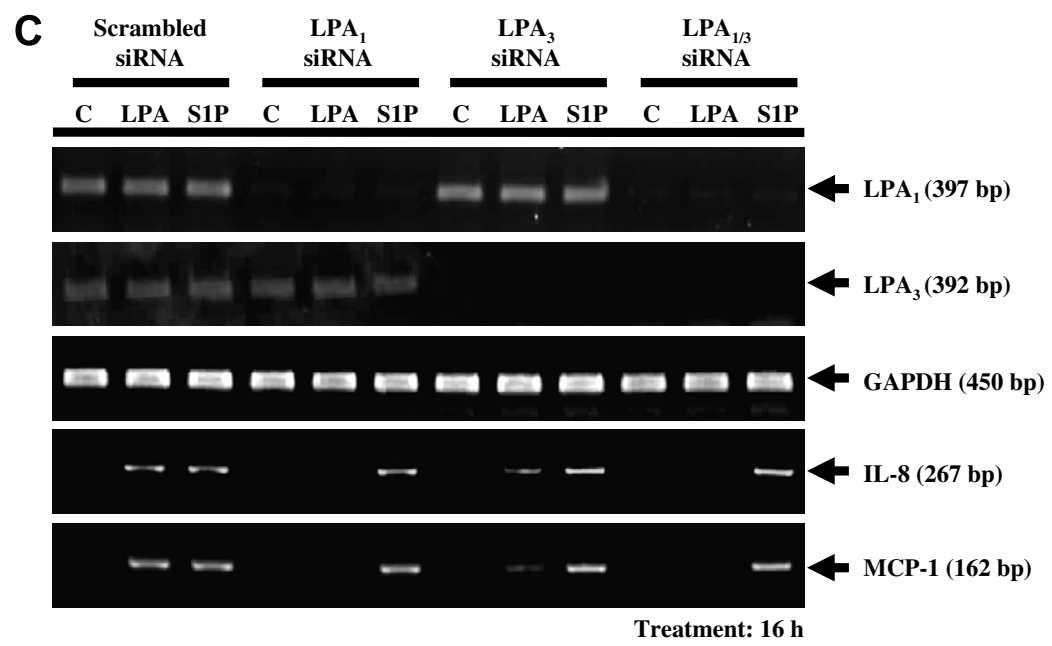

Fig. 1. Effects of LPA receptors siRNAs on ICAM-1, IL-1 $\beta$, IL-8, and MCP-1 mRNA expressions in HUVECs. (A) cDNA of HUVECs was analyzed by RT-PCR to determine the LPA receptor expression profiles. The expected PCR products were 397, 888, and 392 bp for LPA I-3 $_{3}$, respectively. HUVECs were transfected with scrambled, $\mathrm{LPA}_{1}, \mathrm{LPA}_{3}$ or $\mathrm{LPA}_{1}+\mathrm{LPA}_{3}$ siRNA. Twenty-four hours after transfection, HUVECs were starved and treated with $5 \mu \mathrm{M}$ LPA or S1P for $4 \mathrm{~h}(\mathrm{~B})$ or $16 \mathrm{~h}(\mathrm{C})$. ICAM-1, IL-1 $\beta$, IL-8, and MCP-1 mRNA levels were assessed by RT-PCR and shown in the figure as indicated. The expression level of $\mathrm{LPA}_{1}$ or $\mathrm{LPA}_{3}$ in each panel was used to evaluate the efficiency of each siRNA. The amount of GAPDH was used as a loading control. $\mathrm{C}$ represents the untreated control. 


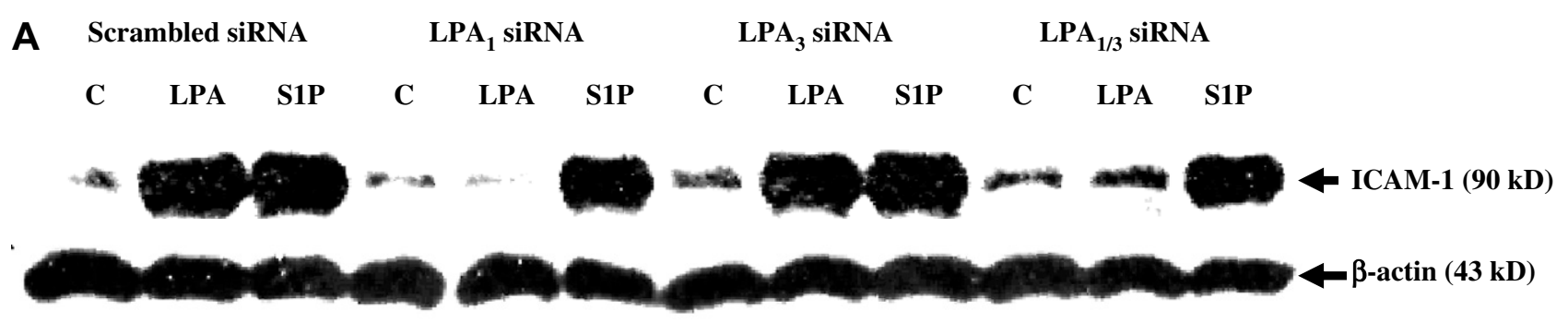

B
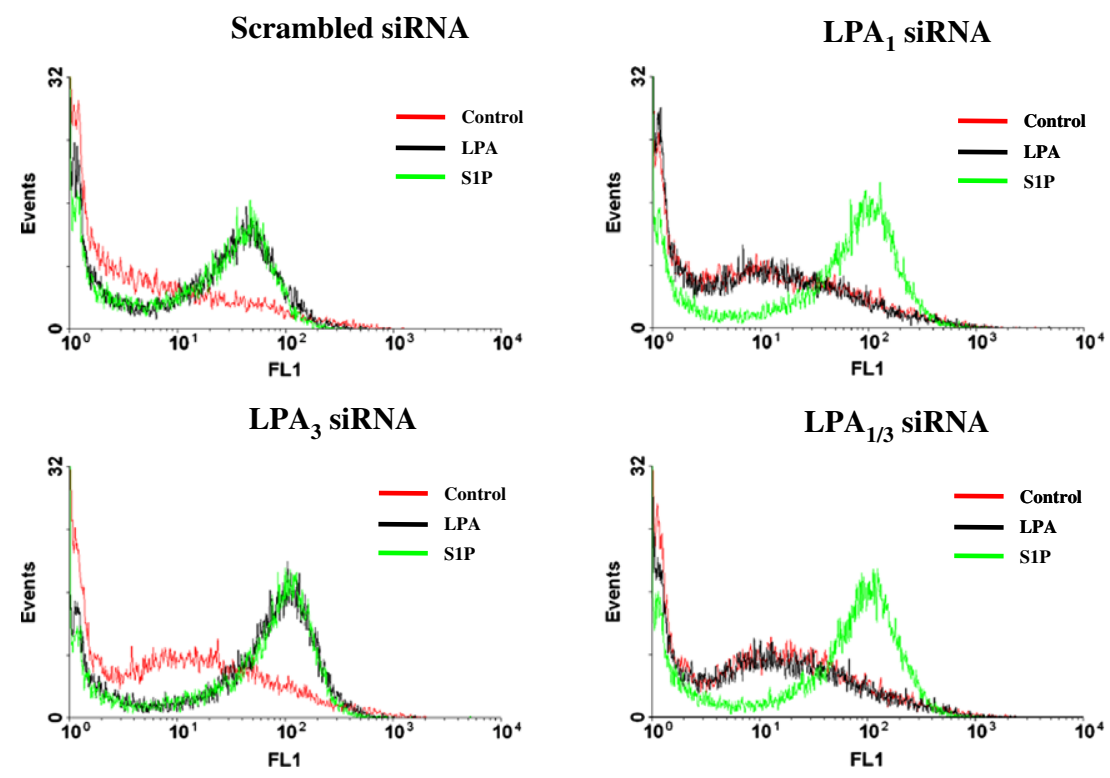

Fig. 2. LPA $_{1}$ siRNAs suppressed total and cell surface ICAM-1 protein expressions in HUVECs. HUVECs were transfected with scrambled, LPA 1 , LPA 3 , or $\mathrm{LPA}_{1}+\mathrm{LPA}_{3}$ siRNA. Transfected HUVECs were starved and treated with $5 \mu \mathrm{M}$ LPA or S1P for $8 \mathrm{~h}$. (A) Total cell lysates were isolated and ICAM-1 protein expression levels were monitored by Western blotting using a human monoclonal anti-ICAM-1 antibody. A human $\beta$-actin antibody was used as the loading control. (B) Treated cells were dissociated by trypsinization and incubated with an FITC-labeled anti-human ICAM-1 monoclonal antibody for 30 min and analyzed by FACscan. C represents the untreated control.

at least $\mathrm{LPA}_{1}$ and $\mathrm{LPA}_{3}$ were expressed in HUVECs (Fig. 1A). Therefore, we first investigated mediation of LPA-induced ICAM-1, IL-1 $\beta$, IL-8, and MCP-1 mRNA expressions by these LPA receptors. siRNA was used to knock down the expression level of a given LPA receptor. HUVECs were transfected with scrambled, $\mathrm{LPA}_{1}, \mathrm{LPA}_{3}$, or $\mathrm{LPA}_{1}+\mathrm{LPA}_{3}$ siRNA. We used S1P, a structural and functional homolog of LPA, as a control in the following experiments. HUVECs transfected with siRNA specific for each LPA receptor showed significantly decreased expression of each LPA receptor mRNA in LPA- and S1P-treated, and untreated samples (Fig. 1B and C). The expression patterns of GAPDH, which was used as the loading control, did not significantly differ in LPA- or S1P-treated, or untreated samples. After $4 \mathrm{~h}$ of treatment, decreases in LPA- but not S1P-induced ICAM-1, IL-8, or MCP-1 mRNA expressions were observed in HUVECs transfected with $\mathrm{LPA}_{1}$ siRNA but not in those transfected with scrambled siRNA. Moreover, LPA- but not S1Pinduced IL- $1 \beta$ mRNA expression in HUVECs was significantly suppressed by transfection with $\mathrm{LPA}_{1}$ or $\mathrm{LPA}_{3}$ siRNA (Fig. 1B). However, LPA-induced IL-8 and MCP-1 mRNA expressions at $16 \mathrm{~h}$ in HUVECs were partially sup- pressed by transfection with $\mathrm{LPA}_{1}$ or $\mathrm{LPA}_{3}$ siRNA (Fig. 1C). These results demonstrated that LPA-regulated ICAM-1 mRNA expression is mediated by $\mathrm{LPA}_{1}$, while LPA-regulated IL-1 $\beta$ mRNA expression is mediated by both $\mathrm{LPA}_{1}$ and $\mathrm{LPA}_{3}$, therefore subsequently modulating long-term IL-8 and MCP-1 mRNA expressions in an $\mathrm{LPA}_{1}$ and $\mathrm{LPA}_{3}$ dependent mechanism in HUVECs.

\section{LPA-induced ICAM-1 protein expression is mediated through $L P A_{1}$ in HUVECs}

Since LPA,'s mediation of LPA-induced ICAM-1 mRNA expression was examined, we further investigated if LPA-elevated mRNA levels of ICAM-1 mediated through $\mathrm{LPA}_{1}$ were also correlated to protein expression levels. Total ICAM-1 protein levels were detected by Western blotting. Decreases in LPA- but not S1P-induced ICAM-1 total protein expression were observed in HUVECs treated with $\mathrm{LPA}_{1}$ siRNA but not those treated with $\mathrm{LPA}_{3}$ siRNA. Co-transfection of $\mathrm{LPA}_{1}$ and $\mathrm{LPA}_{1}$ further totally abrogated LPA-induced ICAM-1 protein expression in HUVECs (Fig. 2A). The expression patterns of $\beta$-actin, which was used as the loading control, did not 
significantly differ in LPA- or S1P-treated, or untreated samples. According to the FACscan analysis, which detects the antigenic activities of proteins on cell surfaces, we also observed a significant decrease in LPA- but not S1Pinduced ICAM-1 cell surface expressions in HUVECs treated with $\mathrm{LPA}_{1}$ and $\mathrm{LPA}_{1}+\mathrm{LPA}_{3}$ siRNA, but not in those treated with $\mathrm{LPA}_{3}$ siRNA (Fig. $2 \mathrm{~B}$ ). These results indicate that the enhancement effects of LPA on ICAM-1 expression mediated through $\mathrm{LPA}_{1}$ also occurred with total protein and cell surface expression in HUVECs.

\section{LPA-enhanced adhesive properties of HUVECs toward U937 cells are mediated through LPA}

In our previous study, we demonstrated that LPLs' enhancement of monocyte adherence to endothelial cells is mediated through upregulating ICAM-1 expression in endothelial cells [12]. In the present study, we found that the enhancement of ICAM-1 mRNA expression by LPA in HUVECs was mediated by $\mathrm{LPA}_{1}$ (Fig. 2). We next attempted to investigate if LPA-induced monocyte adhesion toward endothelial cells is mediated through $\mathrm{LPA}_{1}$. By an in vitro adhesion assay, treatment with scrambled siRNA showed no effects on LPS-activated U937 cell adherence to LPA- and S1P-treated HUVECs. However, treatment with $\mathrm{LPA}_{1}$ but not $\mathrm{LPA}_{3}$ siRNA significantly inhibited U937 cell adherence to LPA- but not S1P-treated HUVECs (Fig. 3). These results illustrate that the enhancement effect of LPA on the adhesive property of endothelial cells toward monocytes is only mediated by activation of $\mathrm{LPA}_{1}$. Our results suggest that $\mathrm{LPA}_{1}$ might mediate LPA-induced ICAM-1 expression in HUVECs and subsequent monocyte-endothelium adhesion.

\section{LPA-enhanced chemotactic activity of HUVECs toward THP-1 cells is mediated through $L P A_{1}$ and $L P A_{3}$}

Our previous study indicated that the enhancement effect of LPA on chemotactic activity of endothelial cell is mediated through upregulation of the expressions of IL-8 and MCP-1 [13]. In addition, LPA-enhanced IL-8 and MCP-1 mRNA expressions were mediated through $\mathrm{LPA}_{1}$ and $\mathrm{LPA}_{3}$ (Fig. 1). Therefore, we further tested the hypothesis that LPA's enhancement of the chemotactic activity in endothelial cells is mediated by $\mathrm{LPA}_{1}$ and $\mathrm{LPA}_{3}$. By a chemotaxis assay, treatment with scrambled siRNA showed no effects on THP-1 cells' transwell migration towards conditioned media of LPA- or S1P-treated HUVECs. However, conditioned media collected from $\mathrm{LPA}_{1}, \quad \mathrm{LPA}_{3}$, or $\mathrm{LPA}_{1}+\mathrm{LPA}_{3}$ siRNA-transfected HUVECs significantly inhibited LPA- but not S1Penhanced THP-1 cell transwell migration (Fig. 4). These results imply that the enhancement effects of LPA on the chemotactic activity of endothelial cell are mediated by $\mathrm{LPA}_{1}$ and $\mathrm{LPA}_{3}$ activation. Our results suggest that $\mathrm{LPA}_{1}$ and $\mathrm{LPA}_{3}$ might mediate LPA-induced IL-8 and MCP-1 expressions in HUVECs, subsequently chemoattracting monocytes toward the endothelium.
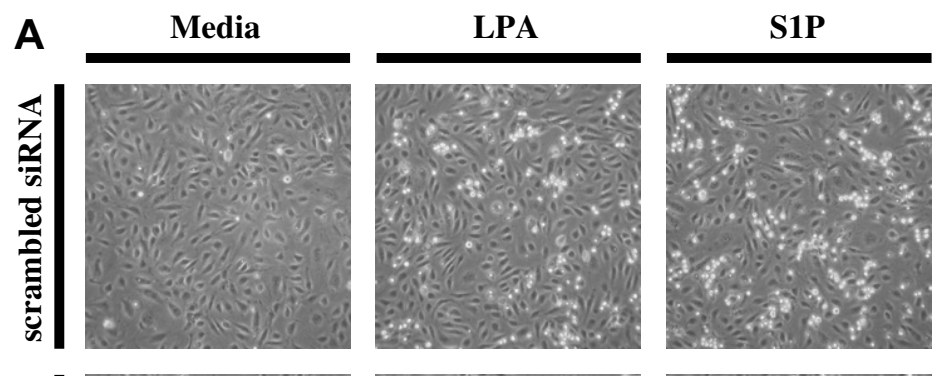

B
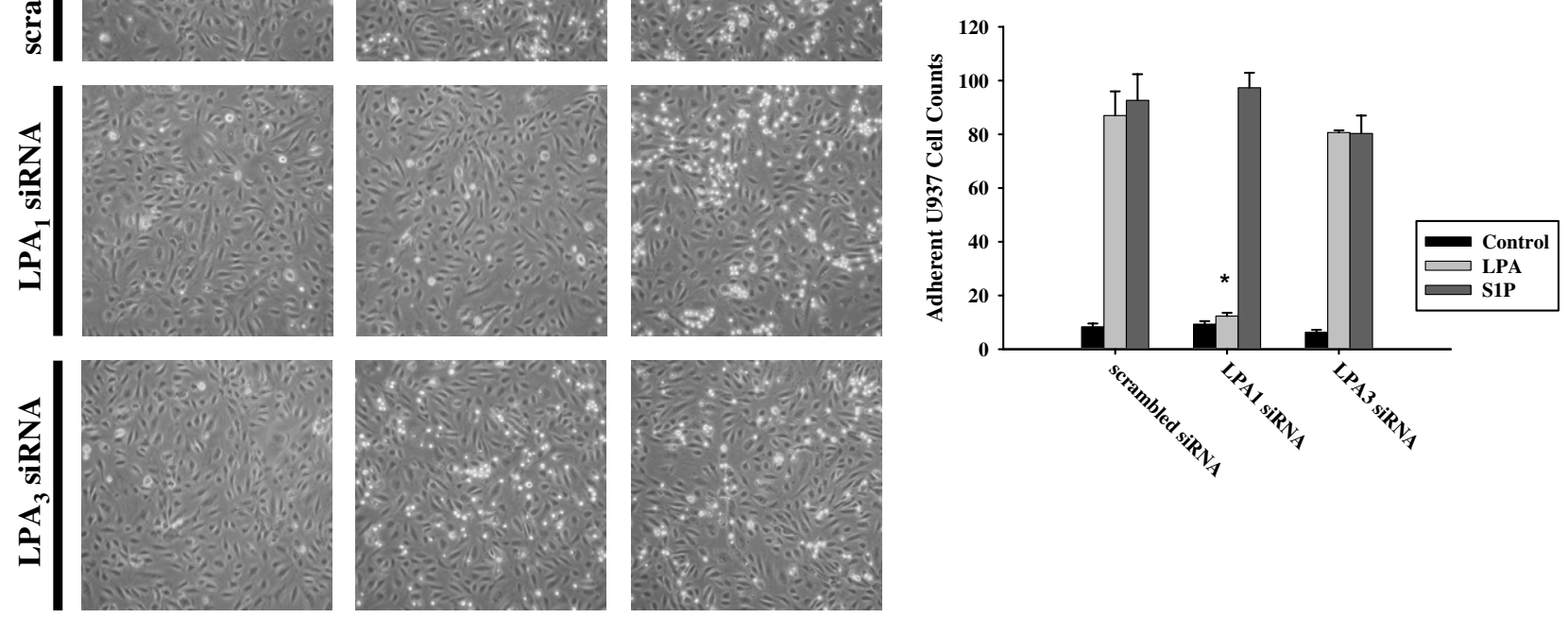

Fig. 3. LPA $_{1}$ siRNAs suppressed LPA- but not S1P-enhanced ICAM-1-mediated U937/HUVEC adhesion. (A) HUVECs were transfected with scrambled, $\mathrm{LPA}_{1}$ or $\mathrm{LPA}_{3}$ siRNA. Transfected cells were treated with medium, $5 \mu \mathrm{M}$ of LPA or S1P for $8 \mathrm{~h}$ and then co-incubated with $1 \mu \mathrm{g} / \mathrm{ml} \mathrm{LPS}-$ stimulated U937 cells for $1 \mathrm{~h}$. (B) Histogram represents quantification of adherent U937 cell counts $\left({ }^{*} p<0.05\right)$. 

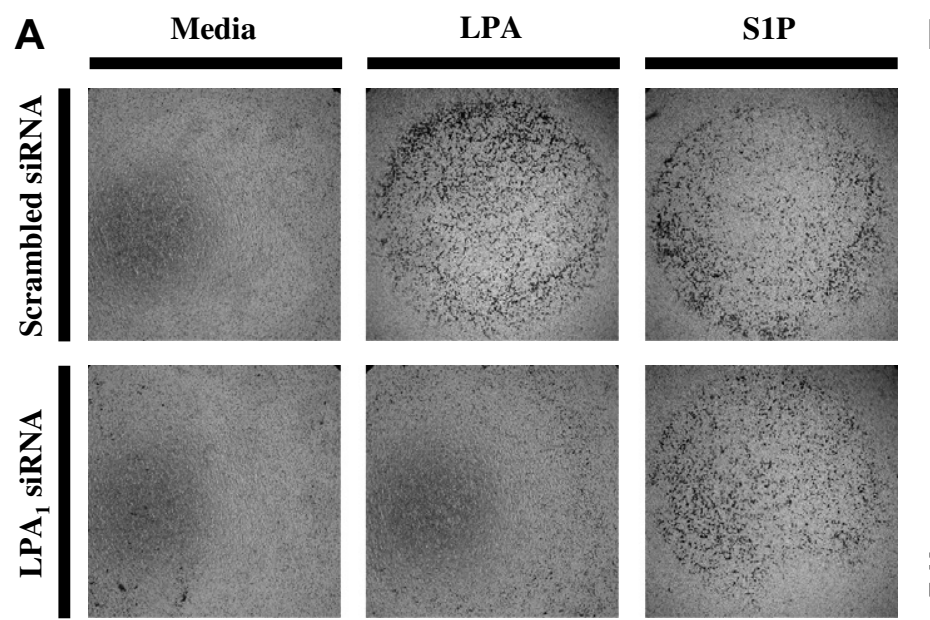

B
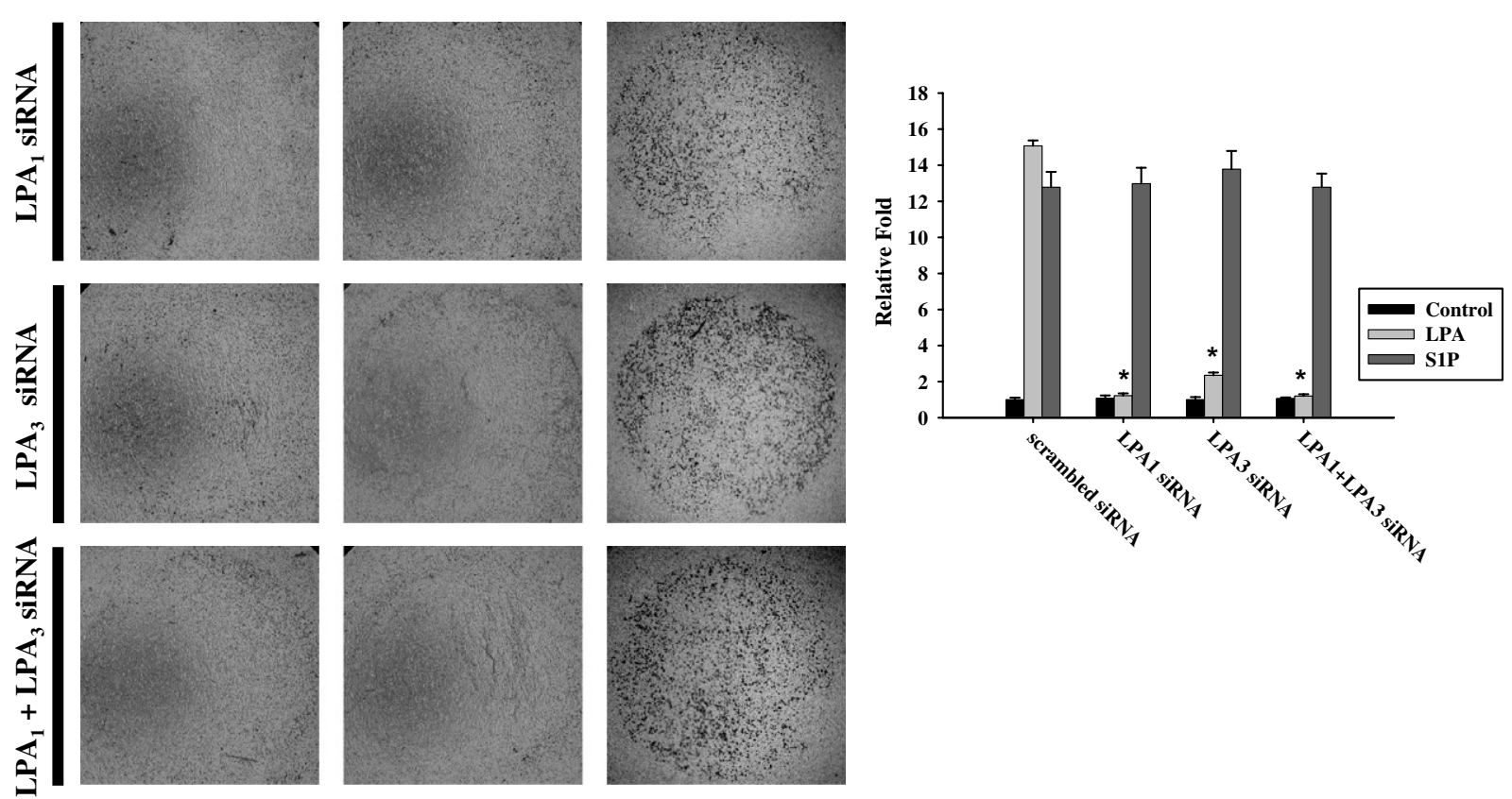

Fig. 4. $\mathrm{LPA}_{1}$ and $\mathrm{LPA}_{3}$ siRNAs inhibit the chemotactic activity of conditioned media from LPA- but not S1P-treated HUVECs. (A) HUVECs were transfected with scrambled, $\mathrm{LPA}_{1}, \mathrm{LPA}_{3}$ or $\mathrm{LPA}_{1}+\mathrm{LPA}_{3}$ siRNA, followed by medium, $5 \mu \mathrm{M}$ of LPA or S1P treatment for $24 \mathrm{~h}$. The chemotactic activity was determined using a 48-well micro chemotaxis chamber. THP-1 cells were added to the upper chambers and allowed to migrate for $4 \mathrm{~h}$ through 8 - $\mu \mathrm{m}$ porous membranes towards the lower chambers which contained the harvested conditioned media which had been added as indicated. Cells migrated to the lower chambers were fixed, stained, and photographed. (B) Histogram represents quantification results of migrating THP-1 cells $\left({ }^{*} p<0.05\right)$. All data are relative multiples of expression compared to untreated cells.

\section{Discussion}

The RT-PCR analysis revealed that not all LPA receptors are expressed in HUVECs. $\mathrm{LPA}_{2}$ (Fig. 1A) was not expressed in HUVECs, which is consistent with previous reports $[2,14]$. In this study, we observed that the effects of LPA treatment for $4 \mathrm{~h}$ on elevating ICAM-1 mRNA expression were mediated by $\mathrm{LPA}_{1}$ but not $\mathrm{LPA}_{3}$, while IL-1 $\beta$ mRNA expression was mediated by both LPA $_{1}$ and $\mathrm{LPA}_{3}$ in HUVECs. However, LPA-induced IL-8 and MCP-1 mRNA expressions at $4 \mathrm{~h}$ were mediated by $\mathrm{LPA}_{1}$, while these enhancement effects at $16 \mathrm{~h}$ were both mediated by $\mathrm{LPA}_{1}$ and $\mathrm{LPA}_{3}$ (Fig. 1). Our previous study demonstrated that LPA's induction of IL-8 and MCP-1 mRNA expressions for $16 \mathrm{~h}$ is IL-1-dependent [13]. Our present results further indicate that LPA-induced IL-8 and MCP-1 mRNA expressions were prolonged to $16 \mathrm{~h}$ due to $\mathrm{LPA}_{1}$ - and $\mathrm{LPA}_{3}$-mediated IL-1 production. However, $\mathrm{LPA}_{1}$ but not $\mathrm{LPA}_{3}$ mediated early direct LPAinduced and IL-1-independent IL-8 and MCP-1 mRNA expressions in human endothelial cells.
A recent study reported that LPA profoundly upregulates IL-8 expression, chemotactic activity, and cell adhesion in DLD1 cells, a cell line exclusively expressing LPA $_{1}$ [18]. Those results further confirm our observation that the LPA-induced adhesive property (Fig. 3) and chemotactic activity (Fig. 4) in endothelial cells were mostly mediated by $\mathrm{LPA}_{1}$ activation. In addition, Zhang et al. reported that the induction of cell proliferation and LPA autocrine in human corneal epithelial cells by LPA or various proinflammatory agonists may be inhibited by pretreatment with pertussis toxin and Ki16425 [19], a selective antagonist of $\mathrm{LPA}_{1}$ and $\mathrm{LPA}_{3}$, which implies that the effect is mainly dependent on $\mathrm{LPA}_{1}$. Gobeil et al. reported that various proinflammatory gene expressions are modulated by nuclear $\mathrm{LPA}_{1}$, implying that either membrane- or nuclear-located $\mathrm{LPA}_{1}$ regulates inflammation processes in response to extracellular or intracellular LPA [20]. These results imply that $\mathrm{LPA}_{1}$ is the most important receptor mediating LPA regulation of various cell functions in different cell types which promote the inflammation process. 
LPA regulates multiple cellular physiological behaviors through binding with LPA receptors. However, not many papers have identified which of these receptors contributes to LPA-regulated cell functions. Our data showed that LPA's induction of IL-8 and MCP-1 mRNA expressions and subsequent chemotactic activities in HUVECs were $\mathrm{LPA}_{1}$ and $\mathrm{LPA}_{3}$ dependent (Figs. 2 and 4). Consistantly, LPA's induction of IL-8 expression was also completely mediated by $\mathrm{LPA}_{1}$ and $\mathrm{LPA}_{3}$, but not $\mathrm{LPA}_{2}$, in human bronchial epithelial cells [21]. In addition, LPA's induction of MCP-1 expression was mainly mediated through $\mathrm{LPA}_{1}$ and $\mathrm{LPA}_{3}$ in human smooth muscle cells [22]. However, $\mathrm{LPA}_{2}$ is the most effective receptor in LPA-induced IL-8 expression in ovarian [23] and colon [24] cancer cells. These results imply that $\mathrm{LPA}_{1}$ and $\mathrm{LPA}_{3}$ might play important roles in IL-8 and MCP-1 expressions, thus regulating inflammation processes, while only $\mathrm{LPA}_{2}$ is essential for IL-8 expression and subsequent cancer cell chemotaxis.

$\mathrm{LPA}_{1}$ and $\mathrm{LPA}_{3}$ expressed on platelets are essential for LPA's presence in the core region of atherosclerotic plaques which triggers rapid platelet activation [25]. Moreover, $\mathrm{LPA}_{1}$ and $\mathrm{LPA}_{3}$ also mediate LPA-regulated eosinophil activation, and the initiation of subsequent inflammation events [26]. Herein, we further report that $\mathrm{LPA}_{1}$ is essential for LPA's regulation of monocyte-endothelial cell adhesion (Fig. 3), and $\mathrm{LPA}_{1}$ and $\mathrm{LPA}_{3}$ are critical for monocyte chemoattraction to the endothelium (Fig. 4), which implies that $\mathrm{LPA}_{1}$ and $\mathrm{LPA}_{3}$ are necessary for endothelial cell interactions with monocytes during inflammation processes. This evidence strongly suggests that $\mathrm{LPA}_{1}$ and $\mathrm{LPA}_{3}$ play critical roles in inflammation process progression, and $\mathrm{LPA}_{1}$ and $\mathrm{LPA}_{3}$ antagonists might also be new targets for anti-inflammation therapeutic drugs.

In summary, our results clearly indicate that LPA increases ICAM-1 mRNA, total protein, and cell surface expressions in human endothelial cells largely mediated by the respective activation of $\mathrm{LPA}_{1}$. Furthermore, LPAenhanced monocytes adhering to endothelial cells are also in an $\mathrm{LPA}_{1}$ dependent mechanism. Through activation of both $\mathrm{LPA}_{1}$ and $\mathrm{LPA}_{3}$, LPA enhanced IL-1 $\beta$ mRNA expression, thus regulating long-term LPA-induced IL-8 and MCP-1 mRNA expression, and subsequent monocyte chemotaxis toward endothelial cells. Our results suggest that $\mathrm{LPA}_{1}$ and $\mathrm{LPA}_{3}$ might be essential receptors for LPA's modulation of monocyte-endothelial cell interactions, which provides valid information necessary for developing new therapeutic drugs against the inflammation process and atherosclerosis formation.

\section{Acknowledgments}

This work was supported by Grants NSC96-2311-B002-018-MY2 (to H. Lee) from the National Science Council, Taiwan, and 96-EC-17-A-19-S1-016 from Department of Industrial Technology, Ministry of Economic Affair, Taiwan (to C. Chen).

\section{References}

[1] W.H. Moolenaar, Bioactive lysophospholipids and their G proteincoupled receptors, Exp. Cell Res. 253 (1999) 230-238.

[2] M.A. Watsky, M. Griffith, D.A. Wang, G. Tigyi, Phospholipid growth factors and corneal wound healing, Ann. NY Acad. Sci. 905 (2000) $142-158$.

[3] H. Lee, E.J. Goetzl, S. An, Lysophosphatidic acid and sphingosine 1phosphate stimulate endothelial cell wound healing, Am. J. Physiol. Cell Physiol. 278 (2000) C612-C618.

[4] T.S. Panetti, J. Nowlen, D.F. Mosher, Sphingosine-1-phosphate and lysophosphatidic acid stimulate endothelial cell migration, Arterioscler. Thromb. Vasc. Biol. 20 (2000) 1013-1019.

[5] S. An, M.A. Dickens, T. Bleu, O.G. Hallmark, E.J. Goetzl, Molecular cloning of the human Edg2 protein and its identification as a functional cellular receptor for lysophosphatidic acid, Biochem. Biophys. Res. Commun. 231 (1997) 619-622.

[6] S. An, T. Bleu, O.G. Hallmark, E.J. Goetzl, Characterization of a novel subtype of human $\mathrm{G}$ protein-coupled receptor for lysophosphatidic acid, J. Biol. Chem. 273 (1998) 7906-7910.

[7] D.S. Im, C.E. Heise, M.A. Harding, S.R. George, B.F. O'Dowd, D. Theodorescu, K.R. Lynch, Molecular cloning and characterization of a lysophosphatidic acid receptor, Edg-7, expressed in prostate, Mol. Pharmacol. 57 (2000) 753-759.

[8] S. An, E.J. Goetzl, H. Lee, Signaling mechanisms and molecular characteristics of $\mathrm{G}$ protein-coupled receptors for lysophosphatidic acid and sphingosine 1-phosphate, J. Cell. Biochem. 30-31 (1998) $147-157$.

[9] K. Noguchi, S. Ishii, T. Shimizu, Identification of p2y9/GPR23 as a novel $\mathrm{G}$ protein-coupled receptor for lysophosphatidic acid, structurally distant from the Edg family, J. Biol. Chem. 278 (2003) 2500625600 .

[10] C.W. Lee, R. Rivera, S. Gardell, A.E. Dubin, J. Chun, GPR92 as a new G12/13- and Gq-coupled lysophosphatidic acid receptor that increases cAMP, LPA5, J. Biol. Chem. 281 (2006) 23589-23597.

[11] J. Chun, E.J. Goetzl, T. Hla, Y. Igarashi, K.R. Lynch, W. Moolenaar, S. Pyne, G. Tigyi, International Union of Pharmacology XXXIV. Lysophospholipid receptor nomenclature, Pharmacol. Rev. 54 (2002) 265-269.

[12] H. Lee, C.I. Lin, J.J. Liao, Y.W. Lee, H.Y. Yang, C.Y. Lee, H.Y. Hsu, H.L. Wu, Lysophospholipids increase ICAM-1 expression in HUVEC through a Gi- and NF-kappaB-dependent mechanism, Am. J. Physiol. Cell. Physiol. 287 (2004) C1657-C1666.

[13] C.I. Lin, C.N. Chen, J.H. Chen, H. Lee, Lysophospholipids increase IL-8 and MCP-1 expressions in human umbilical cord vein endothelial cells through an IL-1-dependent mechanism, J. Cell. Biochem. 99 (2006) 1216-1232.

[14] C. Rizza, N. Leitinger, J. Yue, D.J. Fischer, D.A. Wang, P.T. Shih, H. Lee, G. Tigyi, J.A. Berliner, Lysophosphatidic acid as a regulator of endothelial/leukocyte interaction, Lab. Invest. 79 (1999) 12271235.

[15] S.S. Chae, J.H. Paik, H. Furneaux, T. Hla, Requirement for sphingosine 1-phosphate receptor-1 in tumor angiogenesis demonstrated by in vivo RNA interference, J. Clin. Invest. 114 (2004) 10821089.

[16] J.J. Contos, N. Fukushima, J.A. Weiner, D. Kaushal, J. Chun, Requirement for the LPA1 lysophosphatidic acid receptor gene in normal suckling behavior, Proc. Natl. Acad. Sci. USA 97 (2000) 13384-13389.

[17] C.I. Lin, C.N. Chen, P.W. Lin, H. Lee, Sphingosine 1-phosphate regulates inflammation-related genes in human endothelial cells through S1P1 and S1P3, Biochem. Biophys. Res. Commun. 355 (2007) 895-901.

[18] D. Shida, J. Kitayama, H. Yamaguchi, Y. Okaji, N.H. Tsuno, T. Watanabe, Y. Takuwa, H. Nagawa, Lysophosphatidic acid (LPA) enhances the metastatic potential of human colon carcinoma DLD1 cells through LPA1, Cancer Res. 63 (2003) 1706-1711. 
[19] Z. Zhang, Z. Liu, K.E. Meier, Lysophosphatidic acid as a mediator for pro-inflammatory agonists in a human corneal epithelial cell line, Am. J. Physiol. Cell. Physiol. 291 (2006) C1089-C1098.

[20] F. Gobeil Jr., S.G. Bernier, A. Vazquez-Tello, S. Brault, M.H. Beauchamp, C. Quiniou, A.M. Marrache, D. Checchin, F. Sennlaub, X. Hou, M. Nader, G. Bkaily, A. Ribeiro-da-Silva, E.J. Goetzl, S. Chemtob, Modulation of pro-inflammatory gene expression by nuclear lysophosphatidic acid receptor type-1, J. Biol. Chem. 278 (2003) 38875-38883.

[21] B. Saatian, Y. Zhao, D. He, S.N. Georas, T. Watkins, E.W. Spannhake, V. Natarajan, Transcriptional regulation of lysophosphatidic acid-induced interleukin- 8 expression and secretion by $\mathrm{p} 38$ MAPK and JNK in human bronchial epithelial cells, Biochem. J. 393 (2006) 657-668.

[22] U. Kaneyuki, S. Ueda, S. Yamagishi, S. Kato, T. Fujimura, R. Shibata, A. Hayashida, J. Yoshimura, M. Kojiro, K. Oshima, S. Okuda, Pitavastatin inhibits lysophosphatidic acidinduced proliferation and monocyte chemoattractant protein-1 expression in aortic smooth muscle cells by suppressing Rac-1- mediated reactive oxygen species generation, Vascul. Pharmacol. 46 (2007) 286-292.

[23] X. Fang, S. Yu, R.C. Bast, S. Liu, H.J. Xu, S.X. Hu, R. LaPushin, F.X. Claret, B.B. Aggarwal, Y. Lu, G.B. Mills, Mechanisms for lysophosphatidic acid-induced cytokine production in ovarian cancer cells, J. Biol. Chem. 279 (2004) 9653-9661.

[24] C.C. Yun, H. Sun, D. Wang, R. Rusovici, A. Castleberry, R.A. Hall, H. Shim, $\mathrm{LPA}_{2}$ receptor mediates mitogenic signals in human colon cancer cells, Am. J. Physiol. Cell. Physiol. 289 (2005) C2-C11.

[25] E. Rother, R. Brandl, D.L. Baker, P. Goyal, H. Gebhard, G. Tigyi, W. Siess, Subtype-selective antagonists of lysophosphatidic acid receptors inhibit platelet activation triggered by the lipid core of atherosclerotic plaques, Circulation 108 (2003) 741-747.

[26] M. Idzko, M. Laut, E. Panther, S. Sorichter, T. Durk, J.W. Fluhr, Y. Herouy, M. Mockenhaupt, D. Myrtek, P. Elsner, J. Norgauer, Lysophosphatidic acid induces chemotaxis, oxygen radical production, $\mathrm{CD} 11 \mathrm{~b}$ up-regulation, $\mathrm{Ca}^{2+}$ mobilization, and actin reorganization in human eosinophils via pertussis toxin-sensitive $\mathrm{G}$ proteins, J. Immunol. 172 (2004) 4480-4485. 